\title{
THE DEGREE OF IMPAIRMENT OF FORAGING IN CRAYFISH (Orconectes virilis) DUE TO INSECTICIDE EXPOSURE IS DEPENDENT UPON TURBULENCE DISPERSION
}

Timothy Shane Ludington

\author{
A Thesis \\ Submitted to the Graduate College of Bowling Green \\ State University in partial fulfillment of \\ the requirements for the degree of
}

\section{MASTER OF SCIENCE}

August 2016

Committee:

Paul A. Moore, Advisor

Paul E. Drevnick

Jeffrey G. Miner 
(C) 2016

Timothy S. Ludington

All Rights Reserved 


\section{ABSTRACT}

Paul A. Moore, Advisor

As toxicants move into aquatic systems, the concentration at any point in space or time is heavily influenced by the flow dynamics. The dispersion of these chemicals creates a toxicant concentration that fluctuates widely in time and is highly dependent on the spatial heterogeneity of turbulence. Despite this knowledge on the movement of toxicants in natural systems, most ecotoxicological studies use static exposure paradigms that ignore the spatio-temporal dynamics of toxicants in aquatic systems. Although recent studies have begun to use pulsed paradigms in an attempt to mimic natural conditions, the heterogeneity of real concentrations in natural systems is rarely considered for use in these tests. Thus, understanding how organisms are impaired by naturally distributed toxicants is relatively unknown. The purpose of this experiment was to determine how turbulent dispersion of a toxicant negatively impacts a behavioral task and if altering the nature of turbulence will change the negative impact of the toxicant. Crayfish were exposed to a turbulent plume of carbaryl, an insecticide, under two different turbulent conditions and two different spatial conditions. Turbulence was altered by placing an obstruction within the flow which mimics a natural obstruction in lentic systems. Crayfish were exposed to sublethal concentrations of carbaryl for 48 hours under these different dynamic conditions. After toxicant exposure, crayfish foraging ability was measured in a flow-through Y maze. We hypothesized that crayfish exposed to the toxicant under more turbulent conditions would exhibit more detrimental responses due to the increased variation in chemical fluctuations. The fine-scale chemical distribution of the toxicant as well as the three dimensional velocity profile were characterized for each of the turbulent conditions and each of the spatial locations. Analyses of 
these data showed that changes in turbulence or spatial location created a unique exposure condition. Particularly, significant variations in the rise time, intermittency, and slope of toxicant pulses were quantified, while average concentration of the peaks remained constant across locations. Deficits in the foraging ability of crayfish exposed under these dynamic conditions paralleled the differences quantified in parameters of the turbulent toxicant plume. Given these results, the concept of toxicant exposure needs revision and needs to incorporate the more temporally based measures of toxicant dispersion. In addition, static and pulsed exposure models do not duplicate natural exposure and may not reflect behavioral or physiological impairments that occur under more realistic exposure conditions. 
This thesis is dedicated to auspicious progress and to doing more good than harm. 


\section{ACKNOWLEDGMENTS}

We gratefully thank the University of Michigan Biological Station for the funding support (Marian P. and David M. Gates Graduate Student Fund) that made this study possible and for the use of the stream lab facility. We would also like to thank the members of the Laboratory for Sensory Ecology for their assistance in experimental set-up, and comments. 


\section{TABLE OF CONTENTS}

Page

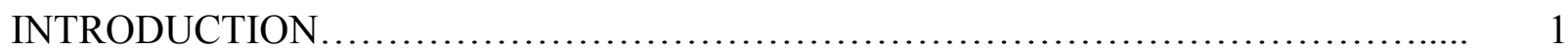

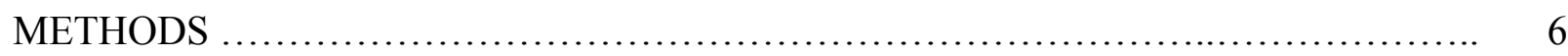

2.1 Animal Collection and Care......................................... 6

2.2 Experimental Design............................................ 6

2.3 Flow-Through Exposure Stream Set-up............................... 7

2.4 Exposure Paradigm.................................................. 8

2.5 Measurement of Chemical Dynamics................................. 9

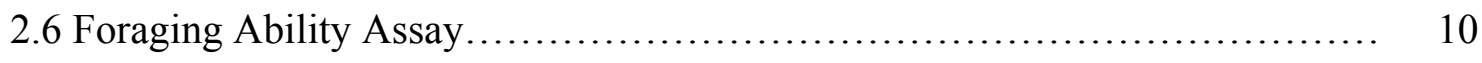

2.7 Physiological Response............................................ 11

2.8 Data Analysis................................................... 12

RESULTS............................................................ 14

3.1 Chemical Plume Dynamics......................................... 14

3.2 Behavioral Effects Due to Carbaryl Exposure............................... 15

3.2.1 Time in Odor Source Arm.................................... 16

3.2.2 Time on Odor Source...................................... 16

3.2.3 Time in Wrong Arm........................................ 16

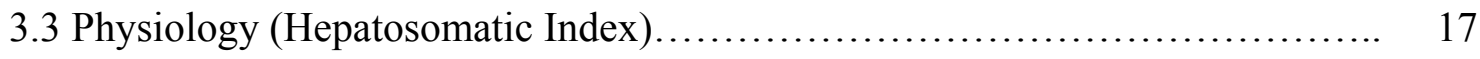

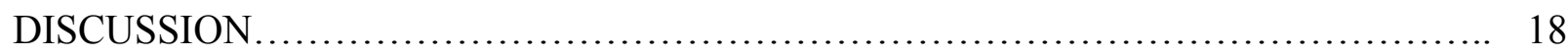

CONCLUSIONS......................................................... 21

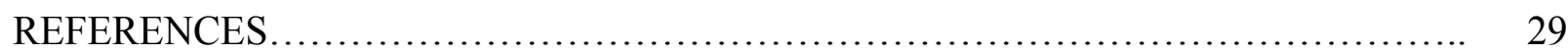




\section{LIST OF TABLE}

Figure

Page

1 Differences between treatment types for parameters of electrochemical plume....... 


\section{LIST OF FIGURES}

Figure $\quad$ Page

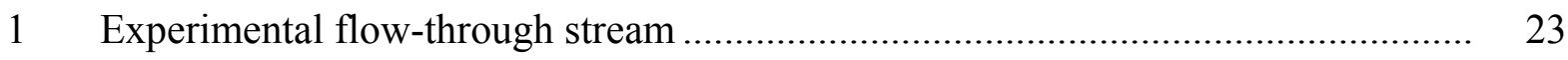

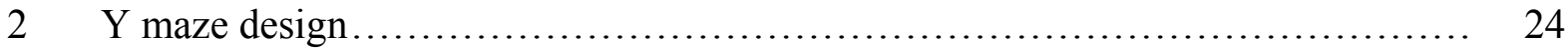

3 Representative chemical signal from tracer plume.......................................... 25

4 Thirty second representative sample from each of the locations measured.............. 26

$5 \quad$ Mean $( \pm$ SEM) of different toxicant plume parameters...................................... 27

6 Mean $( \pm$ SEM) of different foraging behaviors........................... 28 


\section{INTRODUCTION}

Commonly in ecotoxicology research, exposure and the measurement of toxicant impact on organisms has focused on steady-state exposure paradigms (Johnson and Finley 1980; Amiard-Triquet et al. 2015). Steady-state (or static) ecotoxicology tests rely on a set concentration, for a specific period of time, often with no consideration of exposure variability (U.S. Environmental Protection Agency 2002). For example, a broad range of studies used static methods to expose aquatic organisms to a range of concentrations of a toxicant in order to determine LC50 values (Dede and Kaglo 2001; Shahbazzadeh et al. 2009; Ramanujam and Dominic 2012; Rathnamma and Nagaraju 2013). However, these LC50 values do not accurately represent the response of an organism due to exposure in a natural system. In an attempt to provide some fluctuations (frequency) in exposure concentrations, Praskova et al. (2011) used semi - static exposures where the solution was replenished after 24 hours to ensure the concentration remains consistent. Overall these studies neglect the fluctuations that occur under natural conditions. In order to effectively evaluate the consequence(s) of exposure to toxicants in a dynamic system representative of nature, the fluctuation of exposure concentrations needs to be considered.

Introduction of anthropogenic chemicals to natural systems are typically not steady-state (e.g. pesticide runoff from a recently treated agricultural field, industrial chemical spills, and roadway runoff following a rain event). Recently, researchers have begun to evaluate fluctuations of exposure using multiple exposures to mimic the pulsed nature of anthropogenic runoff events (Peterson et al. 2001; Diamond et al. 2006; Hoang et al. 2007; Earl and Whiteman 2009). In these tests, the organisms are exposed to a set concentration for a specified time,

effects are evaluated, and animals are subsequently exposed again to either the same or different 
concentration. Static exposure tests expose organisms to a set concentration while pulsed exposure tests rely on a series of static exposures. Although these pulsed tests are better suited in application to model anthropogenic runoff into streams, there is still the underlying assumption that these exposures are representative of natural lotic conditions. However, chemical plumes entering lotic systems have been documented to greatly fluctuate in intensity (concentration), duration (time), and frequency (rate of exposure) (Milne et al. 2000; Morton et al. 2000; Reinert et al. 2002; Gordon et al. 2012; Edwards and Moore 2014).

Traditionally, static and pulsed ecotoxicology studies have identified intensity, duration, and frequency of chemical fluctuation as the major descriptors of exposure (Handy 1994; Ashauer et al. 2006; Gordon et al. 2012). These three components are dependent upon the turbulent structure of water movement (Weissburg and Zimmer-Faust 1994; Moore and Crimaldi 2004). Intensity, placed within a static exposure test, is the concentration of the chemical within an exposure system (arena, tank, or aquaria) (Gordon et al. 2012). Similarly, duration is the length of time under which an organism experiences a set concentration. Within the newer pulsed paradigms, frequency comingles with intensity and duration to describe the pulsed nature of exposure and indicates the time between two different exposure pulses. In an attempt to further mimic the complexities of chemical dispersion dynamics in nature, researchers have utilized these pulsed exposure paradigms to quantify the impact of frequency on behavioral or physiological impairments (Peterson et al. 2001; Cold and Forbes 2004; Zhao and Newman 2006). Realistically, a pulsed exposure paradigm is just a series of repeated static exposures (Diamond et al. 2005). These paradigms focus on an average toxin concentration, as measured on the scale of an entire stream, and then perform repeated exposures each of which are followed by a clean water or air time period (Jarvinen et al. 1988; Naddy and Klaine 2001). Pulsed 
paradigms are designed to mimic the pulsatile nature of effluent release by a waste water treatment facility or contaminants carried in runoff after a rain event. These paradigms attempt to encompass the three components of exposure (concertation, duration, and frequency). Pulsed paradigms certainly account for the frequency aspects of exposure, but the spatial and temporal scale of the changes in exposure fails to replicate the variation in concentration, duration, and frequency that occurs with the turbulent dispersion of chemicals in flowing systems (Wolf et al. 2009; Edwards and Moore 2014). While the pulsed paradigm is a significant improvement over static exposure paradigms, the pulsed studies still underestimate the degree of heterogeneity that exists in natural systems (Milne et al. 2000). Organisms that inhabit flowing environments do not experience time averaged or even pulsed exposures (Diamond et al. 2005). This rapid fluctuation in concentration is routinely over looked by current evaluation methods (U.S. Environmental Protection Agency 2002).

As chemicals enter a lotic system either through groundwater influx or surface runoff, fluid advection transports the chemical downstream (Moore and Crimaldi 2004; Webster and Weissburg 2009; Lahman and Moore 2015a). In lab and field measurements, chemicals in flow have been observed as heterogeneous plumes with patches varying in concentration (Moore and Atema 1988; 1991; Zimmer-Faust et al. 1988; Moore and Crimaldi 2004; Wolf et al. 2009). The distribution of chemicals in these patchy plumes is highly dependent on turbulence due to the difference between the role of advection and diffusion in moving scalars at a macroscopic scale (Sanford 1997; Edwards and Moore 2014). Turbulence is generated by the diverse elements within a stream, such as runs, riffles, boulders, trees, and other obstacles. Lotic systems vary greatly, in these physical characteristics, across the globe and these variations in the physical nature of lotic systems will generate differing degrees of turbulence, and therefore, create unique 
chemical plumes (Wolf et al. 2009). Few studies have observed this fine-scale distribution of plumes in natural settings (Edwards and Moore 2014).

In order to test the impacts of a spatially and temporally dynamic exposure paradigm on organisms, crayfish were necessary to create a realistic exposure study due to their prevalence in freshwater systems, their interactions with other organisms, as well as their reliance on olfaction for foraging. Crayfish occupy a vital role as ecosystem engineers through their broad diet and their direct and secondary ecosystem effects (Statzner et al. 2003; Dorn and Wojdak 2004; Usio and Townsend 2004). These ecosystem effects range from competition for prey to the mechanical removal of macrophytes in search of higher quality food (Momet 1995). The shredding behavior exhibited during foraging significantly intensifies the breakdown of leaf litter and carbon cycling (Schofield et al. 2001). Additionally, crayfish play an important role as a prey species for fish, birds, and mammals while also serving an economic importance to humans (Jones et al 2006). In addition to their ecological roles, aquatic organisms are affected by contaminants uniquely compared to terrestrial organisms due to the constant contact to the solution. Many studies have also shown that crayfish exhibit reduced foraging abilities after exposure to contaminants (Browne and Moore 2014; Jurcak et al. 2015; Lahman and Moore 2015b).

To test the effects of a contaminant distributed in different levels of turbulence has on behavior of crayfish, the insecticide carbaryl was used. Carbaryl is the third most used pesticide and most used insecticide in the home and garden sector (Grube et al. 2011). This high usage correlates with observations of occurrence in approximately $50 \%$ of urban streams in the United States (Gilliom et al. 2006). The 96 hour LC50 of carbaryl has been measured at 1,900 $\mu \mathrm{g} / \mathrm{L}$ (Johnson and Finley 1980) and at 2,870 $\mu \mathrm{g} / \mathrm{L}$ (Munn et al. 2001). Carbaryl is a reversible 
inhibitor of the enzyme acetylcholinesterase and has a half-life of approximately $10-17$ days in water at $\mathrm{pH} 7$ and is more stable in acidic water $(\mathrm{Xu} 2000)$. The relatively short half-life and high usage made carbaryl an appropriate contaminant to use in this study.

In order to narrow the gap in knowledge that exists in understanding sublethal impairments due to a natural exposure paradigm, we designed a study to investigate how the turbulent dispersal of a toxicant impacts the behavior of a key aquatic organism. This research consisted of two parts: first, the quantification of the dispersal dynamics of a toxicant under different turbulent, flow-through, conditions, and second, an analysis of the behavioral impairments of crayfish under those quantified turbulent conditions. Turbulence was altered in flow-through streams by placing a single obstruction within the flow. We hypothesized that organisms exposed to similar average concentrations of carbaryl would exhibit different behavioral impairments when exposed in different turbulent conditions. These different impairments would be related to the temporal dynamics of the toxicant concentration rather than any average concentration. 


\section{METHODS}

\section{$\underline{2.1 \text { Animal Collection and Care }}$}

Female crayfish [Orconectes virilis $(3.2 \pm 0.03 \mathrm{~cm}$; mean carapace length \pm s.e.m. $)]$ were collected from Burt Lake, Cheboygan County, MI (N 45.4873 W -84.7065) using dip nets. Animals were housed in individual $15 \mathrm{~cm}$ x $10 \mathrm{~cm}$ x $10 \mathrm{~cm}$ plastic containers in a flow-through trough at the University of Michigan Biological Station stream lab research facility, Pellston, MI. Each container had holes to allow for water exchange as well as allowing the animal access to the natural detritus in the stream water. All containers holding animals were placed in the flowthrough housing trough $(5 \mathrm{~m} \times 1 \mathrm{~m} \times 0.5 \mathrm{~m})(1 \times \mathrm{w} \times \mathrm{h})$ constructed from cinder blocks and lined with 4 mil plastic sheeting. All of the water used in this study was pumped directly from the East Branch Maple River and minimally filtered with nylons to remove large particulate matter. Animals were starved for 7 days prior to, and during, the 2-day experimental period to enhance motivation during the foraging behavioral assay.

\section{$\underline{2.2 \text { Experimental Design }}$}

To investigate the effects of turbulent dispersal of toxicants on the behavior and physiology of crayfish, a $2 \times 2 \times 2$ fully factorial experimental design was performed. The first factor was exposure to the toxicant or a control with no toxicant input. The second factor was distance from the head of stream (origin of toxicant source for exposure trials: $51 \mathrm{~cm}$ and 127 $\mathrm{cm})$. The third factor was the absence or presence of a simulated log, which acted as an obstruction to flow generating additional turbulence in the downstream positon. Thus, the experimental design was:

Control, upstream (51 cm from head of stream) without obstruction $\quad \mathrm{N}=15$ Control, upstream (51 cm from head of stream) with obstruction $\quad \mathrm{N}=15$ 


\begin{abstract}
Control, downstream (127 cm from head of stream) without obstruction $\quad \mathrm{N}=15$
Control, downstream (127 cm from head of stream) with obstruction $\quad \mathrm{N}=15$

Exposed, upstream (51 cm from head of stream) without obstruction $\quad \mathrm{N}=15$

Exposed, upstream (51 cm from head of stream) with obstruction $\quad \mathrm{N}=15$

Exposed, downstream (127 cm from head of stream) without obstruction $\mathrm{N}=15$

Exposed, downstream (127 cm from head of stream) with obstruction $\quad \mathrm{N}=15$
\end{abstract}

\title{
2.3 Flow-Through Exposure Stream Set-up
}

Experimental flow-through streams were constructed from cinder blocks (Fig. 1). A total of eight streams were used in this study. Each stream was $180 \mathrm{~cm}$ in length, $40 \mathrm{~cm}$ in width, and maintained at a depth of $20 \mathrm{~cm}$. The cinder block streams were lined with clear 4 mil plastic sheeting and filled with pebbles (mean diameter $1.4 \pm 0.03 \mathrm{~cm}$ ) to maintain a substrate with minimal roughness and a depth of $3 \mathrm{~cm}$. Minimally filtered stream water was pumped from the Maple River, Pellston, MI, into two $200 \mathrm{~L}$ head tanks to maintain a flow velocity of $2.0 \pm 0.5$ $\mathrm{cm} / \mathrm{s}$ through the streams. Stream water was minimally filtered with nylons to remove any large particulate matter that would have compromised the flow of the experimental streams. Water entered the streams, via $3.2 \mathrm{~cm}$ PVC pipes, into a zone of mixing then passed through a collimator designed to condition a stable inflow to the stream. Each collimator was constructed of 2 layers of plastic egg crating $\left(1.7 \mathrm{~cm}^{2}\right.$ holes $)$ wrapped in a fine mesh netting $\left(0.01 \mathrm{~cm}^{2}\right.$ holes $)$. Flow exited the stream via nine $2.5 \mathrm{~cm}$ holes spaced equally in a $2 \mathrm{~cm}$ wide piece of plywood to control the outflow from the stream and therefore control the velocity of water in the stream.

An environment with increased turbulence was achieved by placing a simulated log in the stream to act as an obstruction. The simulated $\log$ was a piece of PVC pipe of $10 \mathrm{~cm}$ diameter $\mathrm{x}$ $40 \mathrm{~cm}$ in length. The simulated log was placed perpendicular to flow, $81 \mathrm{~cm}$ downstream of the 
toxicant point of origin. By analyzing flow patterns of a fluorescent dye in the stream, and locating the position of eddies in the flow due to the simulated log, we were able to determine the area where turbulence had the greatest influence and therefore be the optimal place to restrain the crayfish.

\section{$\underline{2.4 \text { Exposure Paradigm }}$}

An ecologically relevant concentration of carbaryl, $2 \mu \mathrm{g} / \mathrm{L}$ (U.S. EPA 2012; Elias and Bernot 2014) obtained from the commercial insecticide brand Sevin was the toxicant concentration at the location of the crayfish. Carbaryl was introduced into the exposure streams using a Tygon tube $(0.45 \mathrm{~cm}$ ID), buried in the substrate immediately downstream of the collimator. We chose to release the toxicant in the substrate in order to simulate ground water input of contaminated water (Lahman and Moore 2015a). The toxicant was delivered at a constant rate of $7 \mathrm{ml} / \mathrm{min}$ using a Manostat centrifuge pump. Each stream was fed by a separate line ran through a cassette mounted on the Manostat SARAH cassette pump (model number 75500-000; Thermo-Scientific, Barrington, IL) connected to a 5-gallon reservoir of stock solution. Stock solution was prepared to achieve a final carbaryl concentration of $6,000 \mu \mathrm{g} / \mathrm{L}$.

Electrochemical measurements denote a 3,000 factor dilution of stock solution once the plume reaches the exposure location in the streams resulting in the $2 \mu \mathrm{g} / \mathrm{L}$ exposure concentration. The U.S. Environmental Protection Agency (2012) has found that freshwater organisms would be inappropriately protected against an exposure to carbaryl at concentrations greater than $2.1 \mu \mathrm{g} / \mathrm{L}$. Hydrolysis half-life of carbaryl in streams has been calculated to range from 3.8 to 8.3 days (Liu et al. 1981) in lab settings and 1.7 days in a stream with $\mathrm{pH}$ varying from 7.3 to 8.0 (Eichelberger and Lichtenberg 1971). East Branch Maple River water pH was 
measured at 8.1. Due to this rapid degradation of carbaryl and $\mathrm{pH}$ of the East Branch Maple River, new stock solution was prepared each day that exposure trials were conducted.

Although all stream lab water eventually flowed back into the East Branch Maple River, any water containing toxicant was diluted by 5 million L/day output of the stream lab facility; this resulted in a $2 \times 10^{-6}$ fold dilution of the toxicant before entering the East Branch Maple River. Thus discharge rates of carbaryl were minimal and approved by Michigan Department of Environmental Quality water treatment additive permit number MI0050598.

In order to ensure similar exposures in all trials, crayfish were restrained in each exposure arena using a tether (Englund et al. 2000; Kuhlmann et al. 2008). The tether was attached to the animal using hook and loop fasteners and anchored to a clay tile buried under the substrate. The attachment on the animal consisted of a $1 \mathrm{~cm}^{2}$ piece of hook fastener that was secured to the crayfish carapace using a fast drying cyanoacrylate adhesive (Scotch brand super glue). The anchor consisted of a $1 \mathrm{~cm}^{2}$ piece of loop fastener attached to a $10 \mathrm{~cm}$ length of braided fishing line tied to a snap swivel mounted on a $5 \mathrm{~cm} \times 1 \mathrm{~cm} \times 7 \mathrm{~cm}$ clay tile anchor. This restricted the crayfish's movement and prevented twisting of the line while making negligible impacts on the flow. Previous studies have demonstrated minimal impact on restraining crayfish for this period of time (Kuhlmann et al. 2008). Animals were exposed to the toxicant for a period of 48 hours to mimic the exposure duration that may be experienced due to run-off following a rain event.

\subsection{Measurement of Chemical Dynamics}

Quantifying the concentration of a toxicant in flow was completed by using an Epsilon electrochemical detection system (Epsilon; Bioanalytical Systems, West Lafayette, IN) paired with a microelectrode. This is an established system for measuring the turbulent dispersion of chemicals in situ (Wolf et al. 2009; Edwards and Moore 2014). Dopamine was introduced as a 
tracer chemical to quantify the in-situ distribution within the artificial stream. Given the relative ratios of diffusion and advection to the distribution of chemicals, this tracer can accurately model concentration profiles for the toxicant. The microelectrode was assembled in-house with three 30 $\mu \mathrm{m}$ carbon fibers (Gerhardt et al. 1984; Wolf et al. 2009; Edwards and Moore 2014; Lahman and Moore 2015a). The microelectrode was mounted to a tripod and positioned so that the sampling volume was $5 \mathrm{~cm}$ above the substrate. This position was used because the sensory appendages of the animals used in this study are located at this height in the water column. The tripod legs were positioned on top of the walls of the stream and the probe was lowered into the stream in order to minimize any turbulence that may have been generated by the tripod. The tracer molecule (dopamine) was introduced using the same technique as the toxicant. A DC potential amperometry technique was used to record the electrical signal during the oxidation of dopamine (Moore et al. 1989; Moore and Shao 2000; Kozlowski et al. 2003; Wolf et al. 2009). As dopamine molecules come into contact with the carbon-fiber microelectrode, the molecules are oxidized and release electrons, producing an electrical current that is captured by the Epsilon system. The Epsilon system was set to an applied potential of $500 \mathrm{mV}$ with a noise filter of 100 $\mathrm{mV}$ and recordings were made at a rate of $20 \mathrm{~Hz}$ for 5 minutes. Calibration of the electrode was made with three known static dopamine concentrations $(4.6 \mu \mathrm{M}, 9.2 \mu \mathrm{M}$, and $13.8 \mu \mathrm{M})$ in a solution of water from the East Branch Maple River within a laboratory setting. The resulting calibration data provided a linear relationship of electrical current and dopamine concentration for conversion of current recordings into chemical concentrations.

\subsection{Foraging Ability Assay}

Foraging ability was measured using a flow-through Y maze measuring $110 \mathrm{~cm} \mathrm{x} 42 \mathrm{~cm}$ x $8 \mathrm{~cm}$ (Fig. 2). A divider separated the inflow portion of the arena into two equal arms $(71 \mathrm{~cm} \mathrm{x}$ 
$21 \mathrm{~cm} \mathrm{x} 8 \mathrm{~cm}$ ); the arm with the food odor source was termed the correct arm and the arm without the food odor source was termed the wrong arm. The Y maze was constructed out of opaque acrylic and lined with black aquarium gravel to maintain a homogenous substrate. Flow into each arm was initiated by a $4 \mathrm{~L}$ head tank draining at a rate of $150 \mathrm{ml} / \mathrm{min}$; flow rate was driven by a constant pressure head height of $1 \mathrm{~m}$. A Sony Handycam (HDR-CX405) camcorder was used to record the trial. Recordings of trials were viewed to determine amount of time the animal spent in the odor source arm, time in non-odor source arm, time to reach the odor source, and time spent on the odor source (physically touching the food source).

Prior to the start of the trial the exposed crayfish was placed in the common area of the $\mathrm{Y}$ maze (Fig. 2) and allowed to explore the Y maze during a 15-minute acclimation period, crayfish were relocated to the common area at the start of the trial. A sardine gelatin was used as an attractive odor source in the $\mathrm{Y}$ maze for the animal to orientate toward. The gelatin was prepared by blending 47 grams of sardines and 4 packets of Knox brand gelatin then adding the solution to $600 \mathrm{ml}$ of boiling water (Wolf et al. 2004). The liquid was poured into $2 \mathrm{~cm}^{3}$ bottle caps and refrigerated for 12 hours to solidify the gelatin. The trial persisted for 15 minutes and the sardine gel was removed after the trial to quantify mass of food consumed.

\subsection{Physiological Response}

To investigate any potential physiological effects of different exposure conditions, crayfish were analyzed to determine hepatosomatic index (HSI) (Lopez Greco and Rodíguez 1999; Sokolowicz et al. 2006). Immediately following the foraging assay, crayfish were euthanized by freezing. One hour after euthanasia, crayfish were thawed and a total wet body mass was recorded. Chelae were removed and crayfish were massed again to account for any heterogeneity in chelae size. The carapace was removed using dissecting shears and the 
hepatopancreas was removed. Wet masses were recorded of hepatopancreas and this value was divided by body mass to generate the HSI (wet hepatopancreas mass/body mass = HSI) (Da Costa and Ruby 1984).

\subsection{Data Analysis}

To analyze the effects of exposure to the toxicant, a three way MANOVA was used to test the interactions effect of exposure (exposed/ non-exposed crayfish) x location (upstream/ downstream) $\mathrm{x}$ treatment (obstruction/ no obstruction in stream) on behavioral response data. Behavioral measures where the crayfish did not perform the behavioral task (for example, time on source when the animal never entered the source arm) were removed from analysis.

Electrochemical data that were converted to dopamine concentrations were trimmed of the first 10 seconds of data (200 data points) in order to account for the stabilization of the electrode after initial charge. A baseline of the signal was constructed by averaging the signal at the lowest points. Normalization of the dataset was achieved by subtracting the baseline. An inhouse program analyzed the electrochemical plume for parameters defined by Moore and Atema (1991). The recorded time--series data were deconstructed to the explicit peaks that occur above a specific threshold, defined based on the thresholds of chemoreceptor cells of aquatic organisms (Ache 1982). This allowed the analysis to focus only on peaks that are relevant to the exposure the crayfish experienced. Height (maximum concentration), length, rise time (time from the start of the peak to the peak of concentration), absolute slope (height/rise time), and intermittency (time between peaks) for each peak was calculated. Parameters of electrochemical plume are described in Fig. 3. Peak height represents the maximum concentration of which an organism is exposed during the time above threshold. Peak length is the time period during which a peak is above threshold. The rise time is the period of time from the start of a peak (concentration rising 
above threshold) to the peak height. The absolute slope is the peak height divided by the rise time and the intermittency is the period of time between peaks where the concentration is below a threshold. Finally, maximum slope is the largest slope (over $1 \mathrm{sec}$ ) that occurs during the rising phase of the peak. The number of peaks varied for each of the exposure locations (Chi-squared $=$ $30.35, \mathrm{p}<0.05)$. One hundred and ninety total peaks were identified. This included 20 peaks downstream of the obstruction, 72 peaks downstream of no obstruction, 60 peaks upstream of the obstruction, and 38 peaks upstream of no obstruction. Following the initial MANOVA (see above), evaluation of the differences in peak parameters as well as differences in behavioral responses for only exposed crayfish was completed using a 2 × 2 factorial analysis of variance (ANOVA, Statistica version 13; Statsoft Inc., Tulsa, OK) and a Fisher least-significant differences (LSD) post hoc test. Parameters that were not normally distributed were normalized with a square root transformation. A planned comparison was performed on each of the individual variables of behavior by using a two-sample t-test assuming equal variances and a modified p score (Dunn-Sidak correction). 


\section{RESULTS}

\section{$\underline{3.1 \text { Chemical Plume Dynamics }}$}

Tracer plume electrical signals collected at each of the exposure locations were converted to concentration using the calibration curve and plotted against time. Graphs representative of this are shown in Fig. 4. Tracer plumes measured in the two upstream exposure treatments (upstream of an obstruction and upstream of no obstruction) showed no significant difference in peak height, peak length, peak rise time, absolute slope of peaks, or maximum slope of peaks (Fig. 5 A-E). Intermittency of peaks was significantly longer in the upstream positions for the obstruction treatment (Fig. 5F).

Significant differences in the values for plume components were found between the different flow conditions for the downstream locations. Peak height (a proxy for concentration) was not significantly different between the two upstream positions or between the two downstream positions. For all other measures of plume components, the two downstream locations differed significantly. The downstream location with an obstruction had faster peak lengths, faster rise times, longer intermittency between peaks, greater absolute slopes, and greater maximum slopes than the locations downstream of no obstruction (Table 1). 
TABLE 1 Differences between treatment types for parameters of electrochemical plume as described in Fig. 5 A-F

\begin{tabular}{|c|c|c|c|c|c|}
\hline $\begin{array}{l}=\text { Plume } \\
\text { parameters }\end{array}$ & Position & $\begin{array}{l}\text { Mean } \pm \\
\text { s.e.m. }\end{array}$ & Position & $\begin{array}{l}\text { Mean } \pm \\
\text { s.e.m. }\end{array}$ & Statistics \\
\hline \multirow[t]{3}{*}{ Height } & \begin{tabular}{|l|} 
Upstream \\
No Obstruction \\
\end{tabular} & $4.2 \pm 0.6$ & $\begin{array}{l}\text { Upstream } \\
\text { Obstruction }\end{array}$ & $5.1 \pm 0.6$ & $\begin{array}{l}t_{(96,0.05)}=1.04 \\
p=0.15\end{array}$ \\
\hline & \begin{tabular}{|l|} 
Downstream \\
No Obstruction \\
\end{tabular} & $2.1 \pm 0.1$ & $\begin{array}{l}\text { Downstream } \\
\text { Obstruction }\end{array}$ & $2.5 \pm 0.5$ & $\begin{array}{l}t_{(90,0.05)}=0.96 \\
p=0.17\end{array}$ \\
\hline & \begin{tabular}{|l} 
Upstream \\
All \\
\end{tabular} & $4.8 \pm 0.4$ & $\begin{array}{l}\text { Downstream } \\
\text { All }\end{array}$ & $2.2 \pm 0.2$ & $\begin{array}{l}\mathrm{t}_{(188,0.05)}=-5.62 \\
\mathrm{p}<0.001\end{array}$ \\
\hline Length & \begin{tabular}{|l|} 
Downstream \\
No Obstruction \\
\end{tabular} & $2.3 \pm 0.2$ & $\begin{array}{l}\text { Downstream } \\
\text { Obstruction }\end{array}$ & $1.5 \pm 0.1$ & $\begin{array}{l}\mathrm{t}_{(90,0.05)}=-2.19 \\
\mathrm{p}<0.05\end{array}$ \\
\hline Rise time & \begin{tabular}{|l|} 
Downstream \\
No Obstruction \\
\end{tabular} & $1.3 \pm 0.1$ & $\begin{array}{l}\text { Downstream } \\
\text { Obstruction }\end{array}$ & $0.7 \pm 0.1$ & $\begin{array}{l}\mathrm{t}_{(90,0.05)}=-2.09 \\
\mathrm{p}<0.05\end{array}$ \\
\hline \multirow[t]{2}{*}{ Intermittency } & \begin{tabular}{|l|} 
Upstream \\
No Obstruction \\
\end{tabular} & $13.9 \pm 2.4$ & $\begin{array}{l}\text { Upstream } \\
\text { Obstruction }\end{array}$ & $8.3 \pm 1.0$ & $\begin{array}{l}\mathrm{t}(96,0.05)=-2.46 \\
\mathrm{p}<0.05\end{array}$ \\
\hline & \begin{tabular}{|l|} 
Downstream \\
No Obstruction
\end{tabular} & $5.6 \pm 0.8$ & $\begin{array}{l}\text { Downstream } \\
\text { Obstruction }\end{array}$ & $27.1 \pm 7.4$ & $\begin{array}{l}\mathrm{t}_{(90,0.05)}=5.07 \\
\mathrm{p}<0.001\end{array}$ \\
\hline $\begin{array}{l}\text { Absolute } \\
\text { slope }\end{array}$ & \begin{tabular}{|l|} 
Downstream \\
No Obstruction
\end{tabular} & $0.6 \pm 0.2$ & $\begin{array}{l}\text { Downstream } \\
\text { Obstruction }\end{array}$ & $5.5 \pm 3.9$ & $\begin{array}{l}\mathrm{t}_{(90,0.05)}=2.30 \\
\mathrm{p}<0.05\end{array}$ \\
\hline $\begin{array}{l}\text { Maximum } \\
\text { slope }\end{array}$ & $\begin{array}{l}\text { Downstream } \\
\text { No Obstruction }\end{array}$ & $11.2 \pm 1.3$ & $\begin{array}{l}\text { Downstream } \\
\text { Obstruction }\end{array}$ & $30.6 \pm 8.9$ & $\begin{array}{l}\mathrm{t}_{(90,0.05)}=3.59 \\
\mathrm{p}<0.001\end{array}$ \\
\hline
\end{tabular}

\subsection{Behavioral Effects Due to Carbaryl Exposure}

Carbaryl was found to have a significantly detrimental effect on crayfish for each of three behavioral responses (time on source $\mathrm{F}_{(7,37,0.05)}=9.6, \mathrm{p}<0.05$, time in source $\operatorname{arm} \mathrm{F}_{(7,37,0.05)}=$ 5.1179, $\mathrm{p}<0.05$, and time in wrong arm $\mathrm{F}_{(7,37,0.05)}=5.07,<0.05$ : Fig. 6 A-C). Exposed crayfish, regardless of location or obstruction showed impairments with all three of the behaviors above. To further investigate the impact of exposure location and obstruction on the behavior of crayfish, only data collect from exposed crayfish were subjected to further analysis. 


\subsubsection{Time in Odor Source Arm}

Crayfish exposed to carbaryl in either upstream location did not spend a significantly different amount on time in the food odor source $\operatorname{arm} \mathrm{t}(28,0.05)=0.24, \mathrm{p}=0.41$. The crayfish that were exposed to carbaryl downstream of the obstruction spent significantly less time in the odor source arm than the crayfish exposed to carbaryl downstream of no obstruction $t(28,0.05)=-1.91, p$ $<0.05$.

\subsubsection{Time on Odor Source}

Time spent on the food source differed for crayfish as a result of exposure at different locations as well as different obstruction treatments (presence/absence of an obstruction). Crayfish exposed to carbaryl downstream of an obstruction spent significantly less time on the food source that the crayfish exposed to carbaryl downstream of no obstruction $t_{(14,0.05)}=-1.77, p$ $<0.05$. In these streams with no obstructions, crayfish exposed at the downstream location spent significantly more time on the food source than the crayfish exposed in the upstream positions. The amount of time spent on the odor source for crayfish exposed in the either upstream positions did not differ significantly $\mathrm{t}_{(14,0.05)}=-0.31, \mathrm{p}=0.38$.

\subsubsection{Time in Wrong Arm}

The amount of time spent in the wrong arm (no food odor) did not differ significantly for crayfish exposed to carbaryl in either of the upstream locations $t_{(28,0.05)}=-0.65, p=0.26$. Crayfish exposed to carbaryl in the locations downstream of an obstruction spent significantly more time in the wrong arm than those crayfish exposed to carbaryl at the location downstream of no obstruction $\mathrm{t}_{(28,0.05)}=2.14, \mathrm{p}<0.05$. 


\section{$\underline{3.3 \text { Physiology }}$}

Hepatosomatic Index (HSI)

To ensure that the heterogeneity of chelae size and weight did not influence this index, all HSI calculations were performed using entire body mass minus the mass of the chelae. HSI for crayfish exposed to carbaryl downstream in either treatment did not significantly differ $\left(\mathrm{t}_{(28,0.05)}=\right.$ $-0.70, \mathrm{p}=0.24)$ 


\section{DISCUSSION}

Our results clearly show three things. First, that carbaryl, at sublethal concentrations, significantly impacts crayfish behavior. The interaction between exposure to carbaryl and the location of exposure led to significant differences in foraging ability. Second, the exact nature of the impact is determined by turbulent dispersal of the toxicant. Crayfish that were exposed in a more turbulent environment, such as behind an obstruction, show significantly greater deficits in foraging ability when compared to crayfish that were exposed to the toxicant in a less turbulent environment (Fig. 6 A-C). Foraging abilities were impaired as evidenced by the increased time in the non-food arm of the Y maze and the decreased time spent in the arm of the Y maze that contained the food. Third, that peak rise time, intermittency, and absolute slope are more predictive of impairments due to a toxicant than concentration. Increased turbulence did not have an effect of the average concentration of toxicant present in any of the downstream locations. However, increased turbulence altered chemical dispersion dynamics such that peak length, rise time, intermittency, absolute slope, and maximum slope were significantly different between the downstream exposure locations.

The observed deficits in foraging ability show that crayfish exposed to a toxicant in more turbulent environments will have to spend more time foraging to gain the same resources than crayfish exposed in less turbulent conditions. An increase in the amount of time spent foraging increases the chance of an encounter with a predator (Brown and Kotler 2004) and decreases in proportion of time allocated to reproduction behaviors (Pecor and Hazlett 2008). These sublethal effects of exposure can lead to larger scale and more detrimental behaviors (e.g. changes in the locomotory abilities can lead to increased predation or decreased foraging) (Relyea, 2003; Browne and Moore 2014). 
As a toxicant disperses in turbulent flow, the fine-scale spatio-temporal components of the plume will depend upon the exact nature of turbulence. Turbulence in flow generates eddies that serve to stir and mix scalars, like toxicants, and the degree of mixing or stirring is due to the size and structure of turbulent eddies (Sanford 1997; Moore and Atema 1991). These eddies, depending on their size relative to the chemical patches, act to disperse toxicants within the flow. Specific physical attributes of a stream, such as substrate type, generate a range of eddy sizes correlated to the size of the substrate roughness (Wolf and Moore 2009; Edwards and Moore 2014). Heterogeneity of stream structures increase turbulence which, in turn, increase the patchiness of a chemical that is carried in flow. As a result of the above turbulent kinetics, several small-scale features of the chemical dynamics are altered.

Within flowing systems, the interaction of turbulence and chemical dispersion will create fine scale differences in chemical fluctuations (or fluxes). While the average concentration can remain similar at downstream locations (Fig. 4), the temporal fluctuations differ wildly between sites. Our results clearly showed that rise time, length, intermittency, absolute slope, and maximum slope were different at the downstream locations despite similarities in average concentration at these locations. These components of the chemical plume are directly related to the differences in behavioral impairments. The knowledge that the complex concept of toxic exposure is more than a mean concentration is beginning to be established and elements of a dynamic nature (magnitude, frequency, and duration) have been incorporated into the evolving definition of exposure (Gordon et al. 2012). In an attempt to incorporate the frequency of exposure within tests, researchers have exposed organisms to pulsed exposures which is an improvement over static trials (Diamond et al. 2005; Zhao and Newman 2006). Pulsed exposures 
begin to address the dynamic nature of exposure in natural systems but fail to incorporate the flux characteristics (slope, rise time) that are observed in chemical plumes in natural systems.

Thus, taken together, all of these results strongly suggest that exposure (and toxic impact) in naturally flowing systems is related to the dynamic nature of chemical fluctuations. A new description of toxicity and exposure is needed. The classic definition of an LC50 as a set concentration over a set period of time does not capture the dynamic essence of toxicity in naturally flow systems. What is missing from this previous definition of exposure is a deeper analysis of dynamic components of chemical transmission within environments. The interaction of five components of a chemical plume (rise time, length, intermittency, absolute slope, and maximum slope) was shown to correlate with behavioral impairments. Each of these components should be further investigated for their degree of toxicity. 


\section{CONCLUSIONS}

Our results indicate that sublethal concentrations of carbaryl cause significant behavioral responses in $O$. virilis. These behavioral responses were more detrimental for crayfish exposed to carbaryl in environments with increased turbulence. Turbulence within aquatic systems do have an effect on average quantity of toxicant that an animal is exposed to, but the more important point is that turbulence determines the fluctuations of toxicant concentrations. Indeed, our results demonstrate that the fluctuations, and not the average concentration, determine the degree of detriments in animal behavior. Organisms within the same stream reach may experience vastly different exposure paradigms due to the localized turbulence. By measuring the chemical plume in these different regimes, we have found that certain components of the chemical plume correlate with behavioral differences. These components, rise time, intermittency, absolute slope, and maximum slope, have a combined impact on foraging ability in crayfish. In order to fully describe (and ultimately define) the phenomenon of exposure, the impact of each of these components of a chemical plume need to be tested independently. The results from this study will further our understanding of the sensitivity of animal behavior to the dynamic nature of toxicants in natural systems. This dynamic approach to investigating ecotoxicology reflects a more natural state of affairs over using static and average concentrations.

When designing new methods of evaluating the impact of toxicants on organisms in flowing systems, understanding the mechanism by which anthropogenic chemicals enter natural waterways flow through habitats is critical to truly accounting for exposure effects. Toxicants can percolate through soils and contaminate the subsurface flow while surface flow can be contaminated by either point or nonpoint introduction of toxicants. Using the findings from this study, predictions about the effect of exposure can be made by determining which areas of a 
river may be more heavily impacted in the event of a toxicant spill. By focusing on the locations within a flowing habitat with more detrimental effects due to turbulence patterns, remediation efforts may be more effective. 


\section{FIGURES}

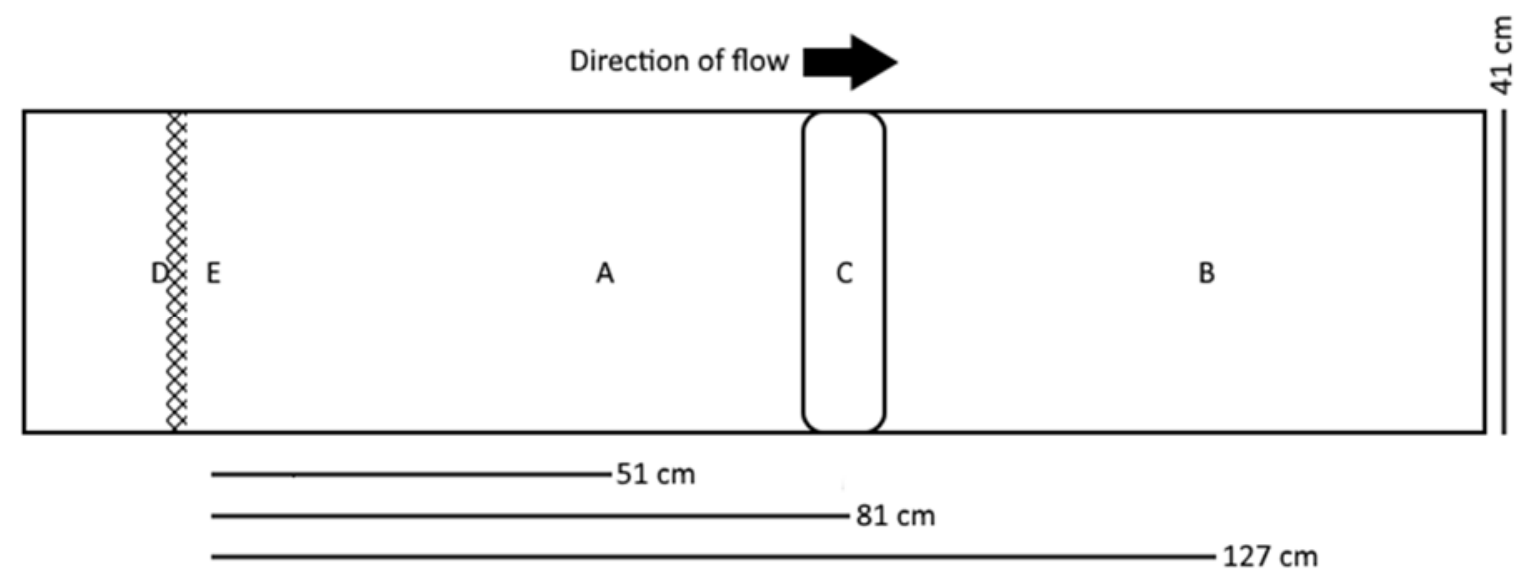

Fig. 1 Experimental flow-through stream. Crayfish were placed at either the upstream (A) or downstream (B) positions. A piece of $10 \mathrm{~cm}$ diameter PVC tubing (C) was placed in streams as the obstruction treatment. Flow was straightened from water entering the stream via a collimator (D). Toxicant was released at $\mathrm{E}$ for toxicant exposure streams. 


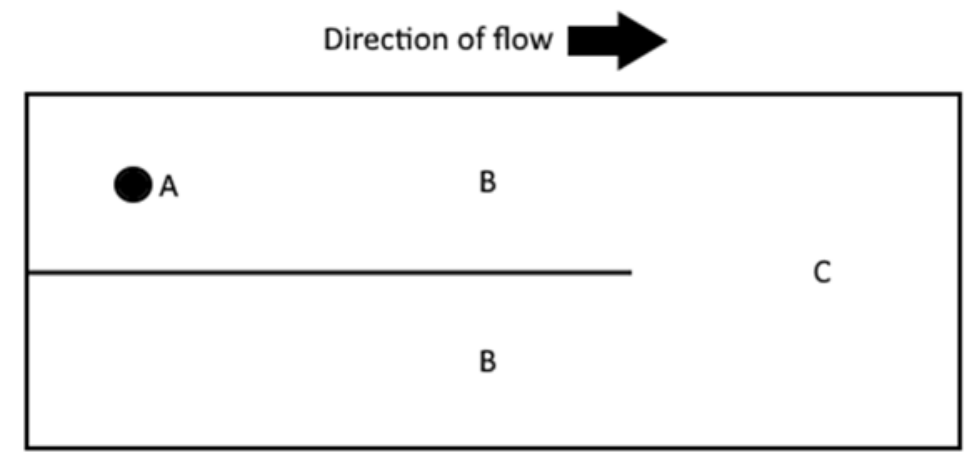

Fig. 2 Y maze design. Flow entered each arm of the Y maze independently and at the same rate from the left side of the image. Discharge was from multiple points spread evenly across the right side of image. A food odor source (A) was placed in a randomly chosen arm (B). Animals were placed in the common area (C) to begin the trial. 


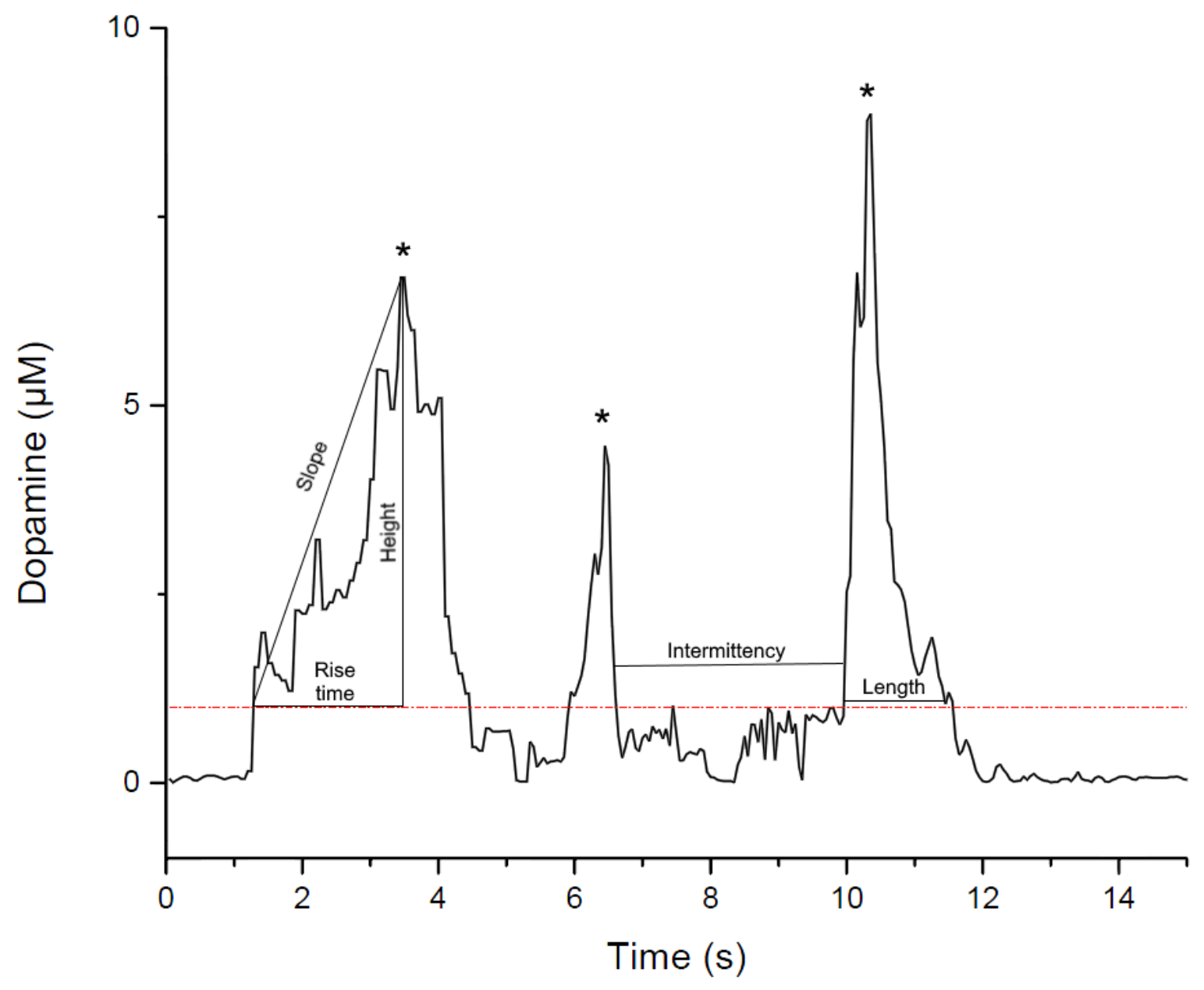

Fig. 3 Representative chemical signal from tracer plume. Peaks are identified by with an asterisk and described by Moore et al. (1989). Peak height was the greatest concentration $(\mu \mathrm{M})$ of tracer that occurred above described threshold (dashed line). Rise time was the amount of time from the start of the peak to the peak height. Absolute slope was the height of the peak divided by the rise time and maximum slope was the largest slope (for $1 \mathrm{~s}$ ) during the entire rise time. Length of each peak was defined as the entire time period that a peak was above the threshold. Intermittency was the time between two successive peaks. 

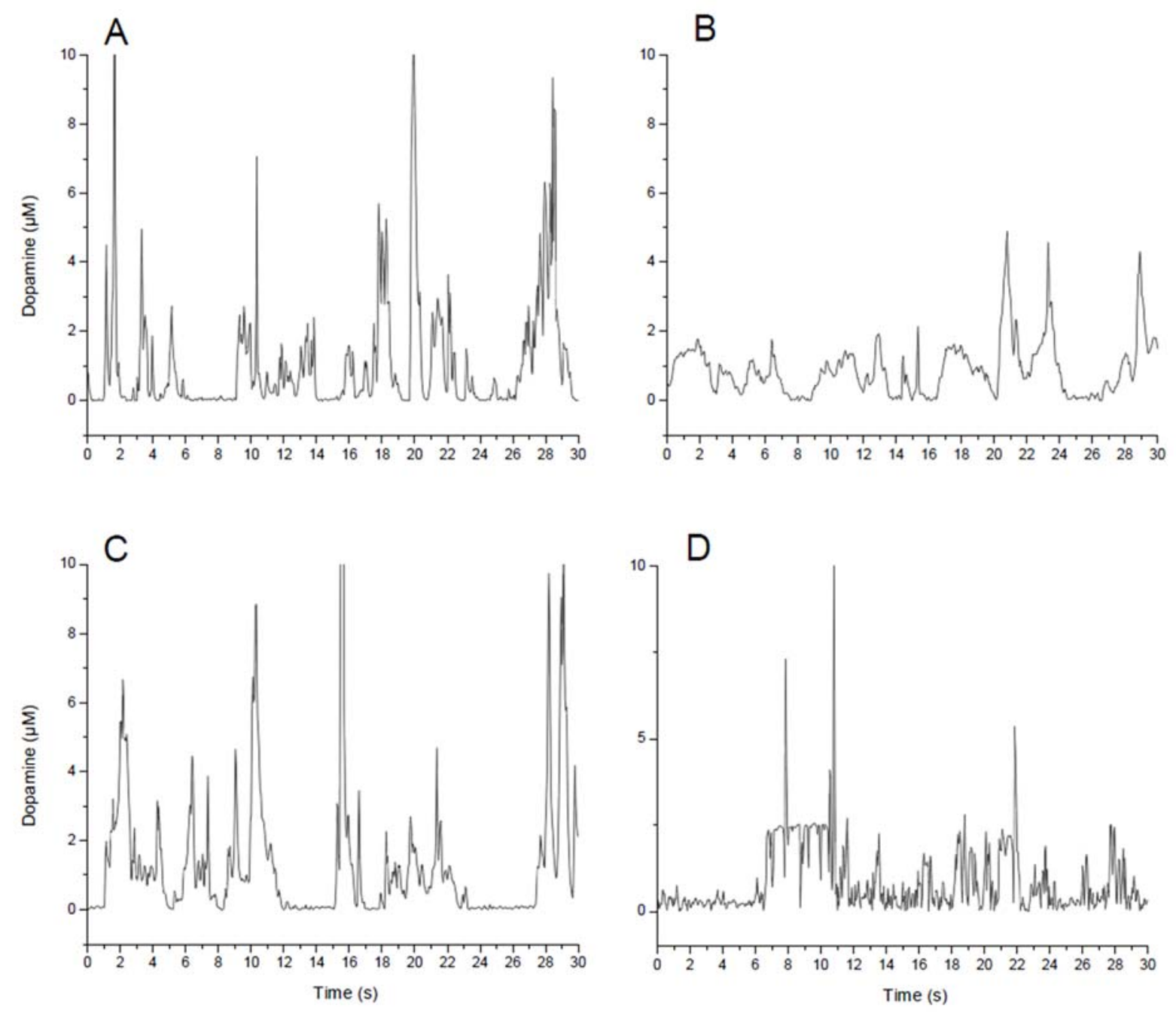

Fig. 4 Thirty second representative sample from each of the locations measured: upstream of no obstruction (A), downstream of no obstruction (B), upstream of an obstruction (C), downstream of an obstruction (D). 

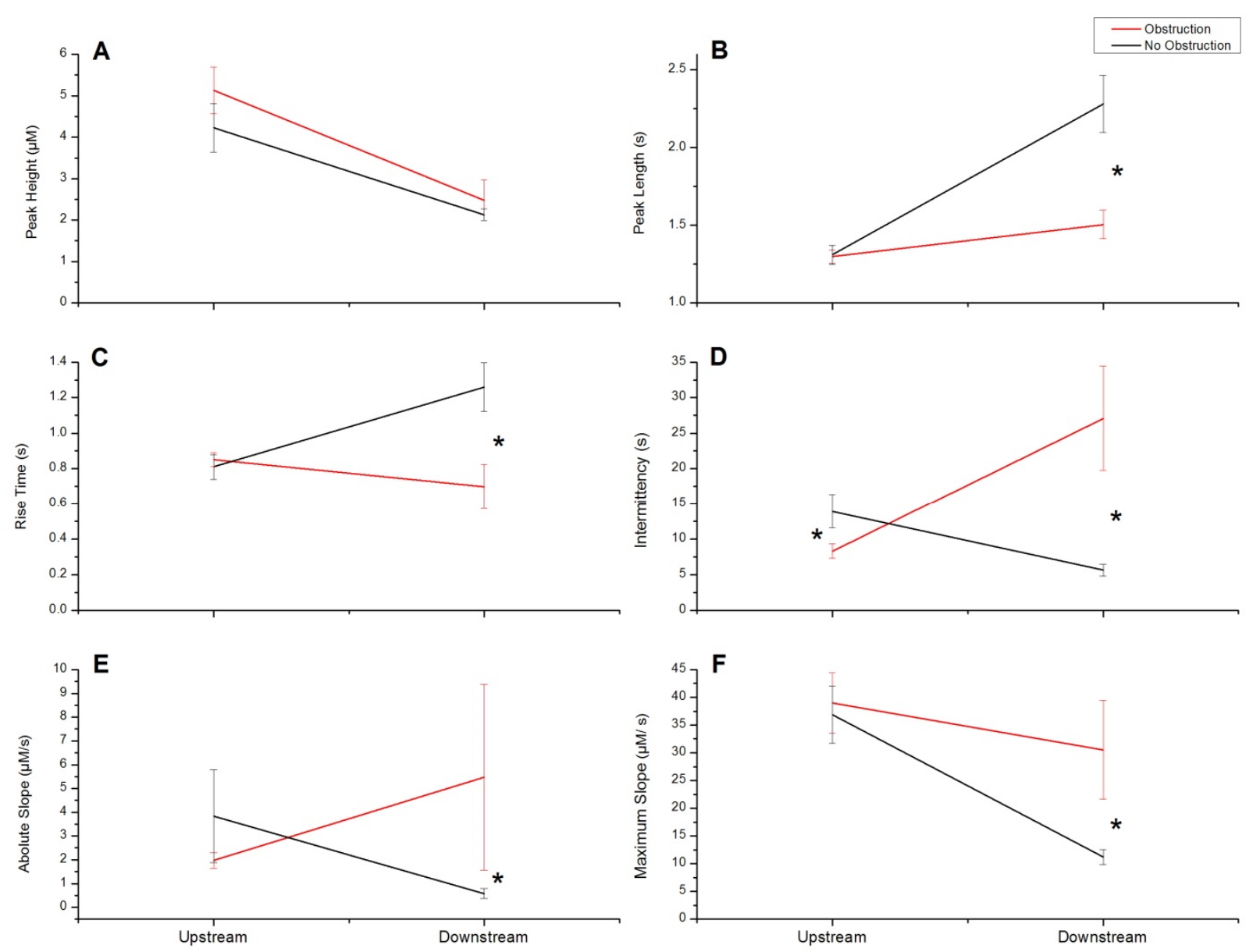

Fig. 5 A-F Mean $( \pm$ SEM) of different toxicant plume parameters for streams with obstructions (red line) and those with no obstructions (black lines). There were no statistical differences between any of the values for peak height (A). Significant differences were found in the values for peak lengths (B), rise time (C), intermittency (D), absolute slope (E), and maximum slope (F) for the two different downstream conditions. Statistical results are outlined in Table 1. Asterisks signify differences between treatments (obstruction/ no obstruction). 


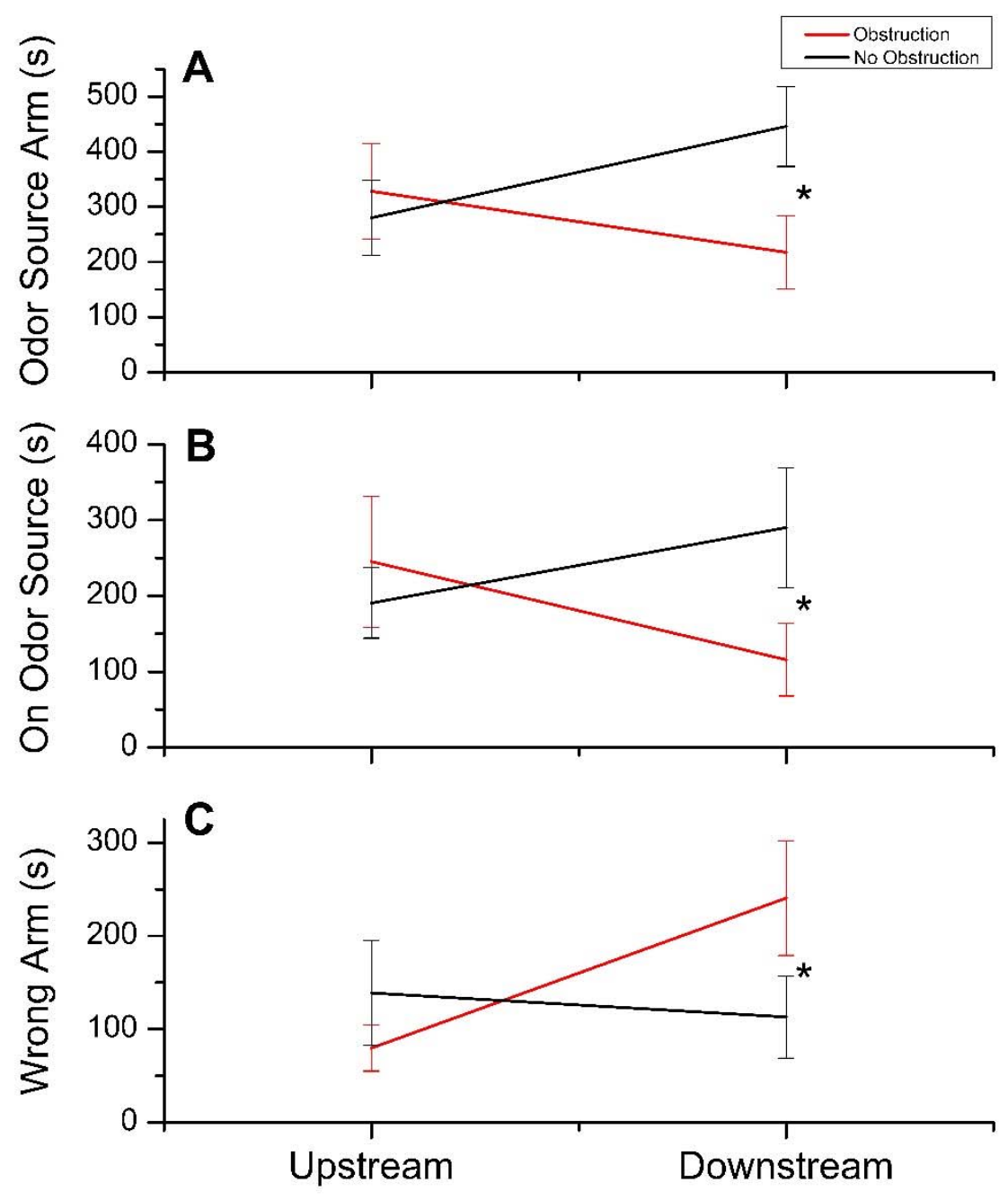

Fig. 6 A-C Mean ( \pm SEM) of different foraging behaviors (time in odor source arm (A), time spent on the odor source (B), and time spent in the wrong arm (C)) exhibited by crayfish exposed at spatial different locations within streams with obstructions (red line) and those with no obstructions (black lines). Asterisks signify differences between treatments (obstruction/ no obstruction) for $\mathrm{At}_{(28,0.05)}=-1.91, \mathrm{p}<0.05, \mathrm{~B} \mathrm{t}_{(14,0.05)}=-1.77, \mathrm{p}<0.05$ and $\mathrm{C} \mathrm{t}_{(28,0.05)}=2.14, \mathrm{p}$ $<0.05$. 


\section{REFERENCES}

Ache, B.W., 1982. Chemoreception and thermoreception. In: Atwood Sandeman (ed) The Biology of Crustacea, vol 3. Neurobiology: Structure and Function. Academic Press, New York, NY, U.S.A. 369-398.

Amiard-Triquet, C., Amiard, J.C., Mouneyrac, C., 2015. Aquatic ecotoxicology: advancing tools for dealing with emerging risks. Academic Press, New York, NY, U.S.A.

Ashauer, R., Boxall, A., Brown, C., 2006. Predicting effects on aquatic organisms from fluctuating or pulsed exposure to pesticides. Environmental Toxicology and Chemistry 25(7), 1899-1912. doi:10.1897/05-393R.1.

Brown, J.S., Kotler, B.P., 2004. Hazardous duty pay and the foraging cost of predation. Ecology Letters 7, 999-1014. doi:10.1111/j.1461-0248.2004.00661.x.

Browne, A.M., Moore, P.A., 2014. The effects of sublethal levels of 2,4-Dichlorophenoxyacetic Acid herbicide (2,4-D) on feeding behaviors of the crayfish O. rusticus. Archives of Environmental Contamination and Toxicology 67, 234-244. doi:10.1007/s00244-014$0032-8$.

Cold, A., Forbes, V.E., 2004. Consequences of a short pulse of pesticide exposure for survival and reproduction of Gammarus pulex. Aquatic Toxicology 67, 287-299. doi:10.1016/j.aquatox.2004.01.015.

Da Costa, H., Ruby, S.M., 1984. The effect of sublethal cyanide on vitellogenic parameters in rainbow trout Salmo gairdneri. Archives of Environmental Contamination and Toxicology 13, 101-104. doi:10.1007/BF01055651. 
Dede, E.B., Kaglo, H.D., 2001. Aqua-toxicological effects of water soluble fractions (WSF) of diesel fuel on O. niloticus fingerlings. Journal of Applied Sciences and Environmental Management 5(1), 93-96. doi:10.4314/jasem.v5i1.54965.

Diamond, J., Bowersox, M., Latimer, H., Barbour, C., Bearr, J., Butcher, J., 2005. Effects of pulsed contaminant exposures on early life stages of the fathead minnow. Archives of Environmental Contamination and Toxicology 49, 511-519. doi:10.1007/s00244-0057023-8.

Diamond, J.M., Klaine, S.J., Butcher, J.B., 2006. Implications of pulsed chemical exposures for aquatic life criteria and wastewater permit limits. Environmental Science \& Technology 40, 5132-5138. doi:10.1021/es0604358.

Dorn, N.J., Wojdak, J.M., 2004. The role of omnivorous crayfish in littoral communities. Oecologia 140, 150-159. doi:10.1007/s00442-004-1548-9.

Earl, J.E., Whiteman, H.H., 2009. Effects of pulsed nitrate exposure on amphibian development. Environmental Toxicology and Chemistry 28(6), 1331-1337. doi:10.1897/08-325.1.

Edwards, D.D., Moore, P.A., 2014. Real exposure: field measurement of chemical plumes in headwater streams. Archives of Environmental Contamination and Toxicology 67(3), 413-425. doi:10.1007/s00244-014-0055-1.

Eichelberger, J.W. Lichtenberg, J.J., 1971. Persistence of pesticides in river water. Environmental Science and Technology 5(6), 541-544. doi:10.1021/es60053a002. 
Elias, D., Bernot, M.J., 2014. Effects of atrazine, metolachlor, carbaryl and chlorothalonil on benthic microbes and their nutrient dynamics. PloS one 9(10), e109190 doi:10.1371/journal.pone.0109190.

Englund, G, Krupa, J.J., 2000. Habitat use by crayfish in stream pools: influence of predators, depth and body size. Freshwater Biology 43, 75-83. doi:10.1046/j.13652427.2000.00524.x.

Gerhardt, G.A., Oke, A.F., Nagy, G., Moghaddam, B., Adams, R.N., 1984. Nafion-coated electrodes with high selectivity for CNS electrochemistry. Brain Research 290, 390-395. doi:10.1016/0006-8993(84)90963-6.

Gilliom, R. J., Barbash, J. E., Crawford, C. G., Hamilton, P. A., Martin, J. D., Nakagaki, N., Nowell, L.H., Scott, J.C., Stackelberg, P.E., Thelin, G.P., Wolock, D. M., 2006. Pesticides in the nation's streams and ground water, 1992-2001 (No. 1291). U.S. Department of the Interior, U.S. Geological Survey.

Gordon, A.K., Mantel, S.K., Muller, N.W.J., 2012. Review of toxicological effects caused by episodic stressor exposure. Environmental Toxicology and Chemistry 31(5), 1169-1174. doi:10.1002/etc.1781.

Grube, A., Donaldson, D., Kiely, T., Wu, L., 2011. Pesticides industry sales and usage. U.S. EPA, Washington, DC, U.S.A.

Handy, R.D., 1994. Intermittent exposure to aquatic pollutants: assessment, toxicity and sublethal responses in fish and invertebrates. Comparative Biochemistry and Physiology 107C (2), 171-184. doi:10.1016/1367-8280(94)90039-6. 
Hoang, T.C., Gallagher, J.S., Tomasso, J.R., Klaine, S.J., 2007. Toxicity of two pulsed metal exposures to Daphnia magna: relative effects of pulsed duration-concentration and influence of interpulse period. Archives of Environmental Contamination and Toxicology 53, 579-589. doi:10.1007/s00244-006-0266-1.

Jarvinen, A.W., Tanner, D.K., Kline, E.R., 1988. Toxicity of chlorpyrifos, endrin, or fenvalerate to fathead minnows following episodic or continuous exposure. Ecotoxicology and Environmental Safety 15, 78-95. doi:10.1016/0147-6513(88)90045-0.

Johnson, W. W., Finley, M. T., 1980. Handbook of acute toxicity of chemicals to fish and aquatic invertebrates: Summaries of toxicity tests conducted at Columbia National Fisheries Research Laboratory, 1965-78 (No. 137). US Fish and Wildlife Service.

Jones, J.P.G., Andriahajaina, F.B., Ranambinintsoa, E.H., Hockley, N.J., Ravoahangimalala, O., 2006. The economic importance of freshwater crayfish harvesting in Madagascar and the potential of community-based conservation to improve management. Oryx 40(2), 168175. doi:10.1017/S0030605306000500.

Jurcak, A.M., Gauthier, S.J., Moore, P.A., 2015. The effects of biodiesel and crude oil on the foraging behavior of rusty crayfish, Orconectes rusticus. Archives of Environmental Contamination and Toxicology 69, 557-565. doi:10.1007/s00244-015-0181-4.

Kozlowski, C., Voight, R. Moore, P.A., 2003. Changes in odour intermittency influence the success and search behavior during orientation in the crayfish (Orconectes rusticus). Marine and Freshwater Behavior and Physiology 36, 97-110. doi:10.1080/1023624031000136279. 
Kuhlmann, M.L., Badylak, S.M., Carvin, E.L., 2008. Testing the differential predation hypothesis for the invasion of rusty crayfish in a stream community: laboratory and field experiments. Freshwater Biology 53, 113-128. doi:10.1111/j.1365-2427.2007.01871.x.

Lahman, S.E., Moore, P.A., 2015a. Fine-scale chemical exposure differs in point and nonpoint source plumes. Archives of Environmental Contamination and Toxicology 68, 729-744. doi:10.1007/s00244-014-0116-5.

Lahman, S.E., Moore, P.A., 2015b. Olfactory sampling recovery following sublethal copper exposure in the rusty crayfish, Orconectes rusticus. Bulletin of Environmental Contamination and Toxicology 95(4), 441-446. doi:10.1007/s00128-015-1623-4.

Liu, D., Thomson, K., Strachan, W.M.J., 1981. Biodegradation of carbaryl in simulated aquatic environment. Bulletin of Environmental Contamination and Toxicology 27, 412-417. doi:10.1007/BF01611041.

Lopez Greco, L.S., Rodíguez, E.M., 1999. Annual reproduction and growth of adult crabs Chasmagnathus granulata (Crustacea, Brachyura, Grapsidae). Cahiers de Biologie Marine 40, 155-164.

Milne, I., Seager, J., Mallett, M., Sims, I., 2000. Effects of short-term pulsed ammonia exposure on fish. Environmental Toxicology and Chemistry 19(12), 2929-2936. doi:10.1002/etc.5620191213.

Momot, W.T., 1995. Redefining the role of crayfish in aquatic ecosystems. Reviews in Fisheries Science 3(1), 33-63. doi:10.1080/10641269509388566. 
Moore, P.A., Atema, J., 1988. A model of a temporal filter in chemoreception to extract directional information from a turbulent odor plume. Biological Bulletin 174(3), 355363.Moore, P.A., Atema, J., 1991. Spatial information in the three-dimensional fine structure of an aquatic odor plume. Biological Bulletin 181(3), 408-418. doi:10.2307/1542361.

Moore, P.A., Crimaldi, J., 2004. Odor landscapes and animal behavior: tracking odor plumes in different physical worlds. Journal of Marine Systems 49, 55-64. doi:10.1016/j.jmarsys.2003.05.005.

Moore, P.A., Gerhardt, G.A., Atema, J., 1989. High resolution spatio-temporal analysis of aquatic chemical signals using microelectrochemical electrodes. Chemical Senses 14(6), 829-840. doi:10.1093/chemse/14.6.829.

Moore, P.A., Shao K., 2000. An electrical circuit model of chemoreceptor cells based on adaptation and disadaptation time constraints: implications for temporal filtering. Materials Science and Engineering 7, 149-160. doi:10.1016/S0928-4931(99)00137-X.

Morton, M.G., Dickson, K.L., Waller, W.T., Acevedo, M.F., Mayer, F.L., Ablan, M., 2000. Methodology for the evaluation of cumulative episodic exposure to chemical stressors in aquatic risk assessment. Environmental Toxicology and Chemistry 19(4.2), 1213-1221. doi:10.1002/etc.5620190455.

Munn, M. D., Gilliom, R. J., Moran, P. W., Nowell, L. H., 2001. Pesticide toxicity index for freshwater aquatic organisms. U.S. Department of the Interior, U.S. Geological Survey. 
Naddy R.B., Klaine, S.J., 2001. Effect of pulse frequency and interval on the toxicity of chlorpyrifos to Daphnia magna. Chemosphere 45, 497-506. doi:10.1016/S00456535(01)00019-4.

Pecor, K.W., Hazlett, B.A., 2008. The tradeoff between reproductive and food resources in the crayfish Orconectes virilis. Marine and Freshwater Behaviour and Physiology 41, 273280. doi:10.1080/10236240802518834.

Peterson, J.L., Jepson, P.C., Jenkins, J.J., 2001. Effect of varying pesticide exposure duration and concentration on the toxicity of carbaryl to two field-collected stream invertebrates, Calineuria californica (Plecoptera: Perlidae) and Cinygma sp. (Ephemeroptera: Heptageniidae). Environmental Toxicology and Chemistry 20(10), 2215-2223. doi:10.1002/etc.5620201013.

Praskova, E., Voslarova, E. Siroka, Z., Plhalova, L., Macova, S., Marsalek, P., Pistekova, V., Svobodova, Z., 2011. Assessment of diclofenac LC50 reference values in juvenile and embryonic stages of the zebrafish (Danio rerio). Polish Journal of Veterinary Sciences 14(4), 545-549. doi:10.2478/v10181-011-0081-0.

Ramanujam. S.N., Dominic, R., 2012. Median lethal concentration (LC50) of piscicidal plants and their utilization in aquaculture. Journal of Applied Aquaculture 24, 326-333. doi:10.1080/10454438.2012.731944.

Rathnamma, V., Nagaraju, B., 2013. Median lethal concentrations (LC50) of Chlorantraniliprole and its effects on behavioral changes in freshwater fish Labeo rohita. International Journal of Public Health Science 2(4), 137-142. 
Reinert, K.H., Giddings, J.M., Judd, L., 2002. Effects analysis of time-varying or repeated exposures in aquatic ecological risk assessment of agrochemicals. Environmental Toxicology and Chemistry 21(9), 1977-1992. doi:10.1002/etc.5620210928.

Relyea, R.A., 2003. Predator cues and pesticides: a double dose of danger for amphibians. Ecological Applications 13(6), 1515-1521. doi:10.1890/02-5298.

Sanford, L.P., 1997. Turbulent mixing in experimental ecosystem studies. Marine EcologyProgress Series 161, 265-293.

Schofield, K.A., Pringle, C.M., Meyer, J.L., Sutherland, A.B., 2001. The importance of crayfish in the breakdown of rhododendron leaf litter. Freshwater Biology 46, 1191-1204. doi:10.1046/j.1365-2427.2001.00739.x.

Shahbazzadeh, D., Ahari, H, Rahimi, N.M., Dastmalchi, F., Soltani, M., Fotovat, M., Rahmannya, J., Khorasani, N., 2009. The effects of Nanosilver (Nanocid ${ }^{\circledR}$ ) on survival percentage of rainbow trout (Oncorhynchus mykiss). Pakistan Journal of Nutrition 8(8), 1178-1179.

Sokolowicz, C.C., Bond-Buckup, G., Buckup, L., 2006. Dynamics of gonadal development of Aegla platensis Schmitt (Decapoda, Anomura, Aeglidae). Revista Brasileira de Zoologia 23(4), 1153-1158. doi:10.1590/S0101-81752006000400023.

Statzner, B., Peltret, O., Tomanova, S., 2003. Crayfish as geomorphic agents and ecosystem engineers: effect of a biomass gradient on baseflow and flood-induced transport of gravel and sand in experimental streams. Freshwater Biology 48, 147-163. doi:10.1046/j.13652427.2003.00984.x. 
U.S. Environmental Protection Agency, 2002. Short term methods for estimating the chronic toxicity of effluents to freshwater organisms. EPA/600/4-91/002, fourth edition. Office of Water, Science and Technology, Washington, DC, U.S.A.

U.S. Environmental Protection Agency, 2012. Aquatic life ambient water quality criteria for carbaryl. EPA/820/R-12/007 Office of Water, Science and Technology, Washington, DC, U.S.A.

Usio, N., Townsend, C.R., 2004. Roles of crayfish: consequences of predation and bioturbation for stream invertebrates. Ecology 85, 807-822. doi:10.1890/02-0618.

Webster, D.R., Weissburg, M.J., 2009. The hydrodynamics of chemical cues among aquatic organisms. Annual Review of Fluid Mechanics 41, 73-90.

doi:10.1146/annurev.fluid.010908.165240.

Weissburg, M.J., Zimmer-Faust, R.K., 1994. Odor plumes and how blue crabs use them in finding prey. Journal of Experimental Biology 197, 349-375.

Wolf, M.C., Martin III, A.L., Simon, J.L., Bergner, J.L., Moore, P.A., 2009. Chemosensory signals in stream habitats: implications for ecological interactions. Journal of the North American Benthological Society 28(3), 560-571. doi:10.1899/08-108.1.

Wolf, M.C., Voigt, R., Moore, P.A., 2004. Spatial arrangement of odor sources modifies the temporal aspects of crayfish search strategies. Journal of Chemical Ecology 30(3), 501517. doi:10.1023/B:JOEC.0000018625.83906.95.

Xu, S., 2000. Environmental fate of carbaryl. California Environmental Protection Agency, Department of Pesticide Regulation, Sacramento. 
Zhao, Y., Newman, M.C., 2006. Effects of exposure duration and recovery time during pulsed exposures. Environmental Toxicology and Chemistry 25(5), 1298-1304. doi:10.1897/05341R.1.

Zimmer-Faust, R.K., Stanfill, J.M., Collard, S.B., 1988. A fast, multichannel fluorometer for investigating aquatic chemoreception and odor trails. Limnology and Oceanography 33(6), 1586-1595. 